\title{
On Value Diffusion in Cross-Cultural TV Commercials Between China and the USA
}

\author{
YANG Ren-ying \\ North China University of Technology, Beijing, China
}

\begin{abstract}
In the global era, especially under the effect of various mass media, people across the world interplay with each other and cultural diffusion exist almost everywhere whether it be seen or not. Cross-cultural TV commercials, as an important marketing strategy, have in essence become a cultural channel to better promote products, in which some alien cultural elements are borrowed to meet the psychological need of the target consumers and be compatible with the target belief and values, meanwhile the source cultural elements of themselves, to some extent, are transmitted and spread. In this process of the cultural contact or diffusion, both source cultural values of one country and the target values of the other are interacted with each other and bring this or that change to its own culture. This paper, with semiotics as well as the cross-culture communication theory, aims to exemplify how the diffusion takes place in the cross-cultural commercials between China and the USA, thus analyzing the characteristics of the current status and further finding out the impacts of the diffusion.
\end{abstract}

Keywords: value diffusion, cross-cultural TV commercials, cross-cultural communication, semiotics

\section{Introduction}

In the global village, cultural interaction has become natural whatever in depth and breadth. And we often find ourselves much alike before we try to explore the differences. Living on the same planet, especially with the spurring development of mass media, diffusion, i.e., the spreading of ideas or products from one culture to another ${ }^{1}$, tends to be pervasive and convenient. This paper mainly focuses on how the cultural diffusion takes place in the cross-cultural TV commercials between China and America.

\section{Diffusion and Assimilation}

Before dealing with the topic, it is necessary to differentiate the two concepts: diffusion and assimilation. Both terms can be regarded as the mechanism of cultural change or the way in which a culture attains ideas, but the former refers to the spreading of ideas or products from one culture to another by accident or choice, and assimilation denotes "the cumulative changes that make individuals of one ethnic group more acculturated, integrated, and identified with the members of another" (Rumbaut, 2005, p. 4). In fact, the two are closely related. To great extent, diffusion contributes to assimilation and cultural assimilation are based on cultural diffusion. According to Samovar and Porter (2000):

YANG Ren-ying, lecturer, Department of Humanities and Law, North China University of Technology.

${ }^{1}$ Retrieved from http://wiki.answers.com/Q/What_is_cultural_diffusion. 
Diffusion $^{2}, \ldots$, is the borrowing by one culture from another... Because cultures want to endure, they usually adopt only those elements that are compatible with their values and beliefs or that can be modified without causing major disruption. The assimilation of what is borrowed accelerates when cultures come into direct regular contact with each other. (p. 45)

Therefore, we can see there is no clear-cut boundary among diffusion and assimilation. However, this paper gives emphasis on the spreading instead of the integrating.

As to the diffusion, there are three types: direct diffusion (it occurs when two distinct cultures are very close together), forced diffusion (it takes place when one culture defeats another and forces its beliefs and customs onto the conquered people), and indirect diffusion (it happens when cultural ideas are spread through a middleman or even another culture $)^{3}$. What this paper concerns falls into the third type since we deal with diffusion from TV commercials, a kind of popular mass media.

\section{About Cross-Cultural TV Commercials}

Culture penetrates into every aspect of our life, including business. In the cross-cultural communication, TV commercials in essence have become a cultural channel to better promote products. That is, when creating and designing a TV commercial, the target cultural factors should be given first consideration so as to meet the psychological needs of the target consumers and be compatible with the target belief and values. However, consciously and unconsciously, when successfully realizing the localization, the source cultural elements, especially cultural values, are given access to the target culture.

It is worth mentioning that TV commercials are powerful and effective with TV, which evolves greatly with the new technology and can reach an audience nationwide. Hence, the spread of cultural values will be fast and effective.

\section{The Relative Studies Conducted}

Since the 1980s, many surveys on cross-cultural advertising between different countries have been conducted. For example, Weinberger and Spotts (1989) comparatively analyzed the information content of British and U.S. television advertising; Cutler and Javalgi (1992) conducted a cross-cultural analysis of the visual components of print advertising from the USA, France, and the $\mathrm{UK}^{4}$. However, these studies are done in earlier periods. With the advancement of era, things have changed, therefore, it is worthwhile reexamining.

As to the comparison survey between China and other countries, it has not been done much, especially in TV commercials. Still, most of the survey is limited in the level of language or advertising itself. This is the very significance of writing this paper, for the study will facilitate the communication with a better understanding of the interaction of the cultural values in different countries.

\section{Case Study on Current Status of Diffusion Between Chinese and American Values}

In this part, the theory of semiotics as well as cross-cultural communication perspectives will be introduced into the case analysis. Here is the brief introduction of the former for the convenience of following the case study. Semiotics is the study of everything that can be used for communication and focuses on how the meaning is

\footnotetext{
${ }^{2}$ It is called cultural contact in Foundations of Intercultural Communication (2007, p. 27) by CHEN Guo-ming and William J. Starosta.

3 Retrieved from http://wiki.answers.com/Q/What_is_cultural_diffusion.

${ }^{4}$ Retrieved from http://www.bookpump.com/dps/pdf-b/1120842b.pdf.
} 
created. The smallest unit of meaning in semiotics is called the sign. Saussure (2003, pp. 66-67) conceptualized the sign as composed of two distinct parts: a signal (the sound pattern) and the signification (the concept it represents). He also stressed that the link between the two is arbitrary. Barthes (1967) further expounded the sign. According to him, denotation is the first order of signification and connotation is a second-order signifying system that uses the first sign as its signifier and attaches an additional meaning, another signified, to it. Therefore, in different cultural contexts, the same sign will be given different connotations. According to Saussurean semiotics, signs are organized into two ways: by syntagmatic relations and associative relations (Saussure, 2001, pp. 121-122). The former stresses the structure and the latter the relevant meaning. Barthes (1967) coded the two relations into syntagma and paradigm respectively.

\section{Case Study 1: Kentucky Commercials vs. Qingdao Beer Commercials}

With the slogan "Life tastes better with KFC", Kentucky has adopted a successful marketing strategy and made Chinese people really taste the pleasure of having the fast food, thus occupying an important place in fast food industry. And the innovative commercials greatly contribute to the sales and spread of the newly introduced food. The commercials, considering the Chinese eating cultural factors, well meet the psychological requirements of most of the Chinese consumers, especially young people. In this paper, we will choose the Pastoral Piece to make a comparison. With the introduction of alien food, we are also promoting our products abroad, Tsingtao Beer is one of the typical examples, and here is the one from CCTV (China Central Television) International.

In the Pastoral Piece, a sweet Chinese girl in check skirt is leisurely playing on a swing against the backdrop of a green and lovely lawn on which stands a well-pruned tree. While she is enjoying the sunshine and the coziness, she is daydreaming who is the right knight in armor and which is the ideal food. And then the exquisite picture of an attractive chicken hamburger in front as well as its various fresh ingredients behind is shown, next is the display of the section of the hamburger, from which we can see the ingredients. The next set of picture is the combo pack with a calendar as the reward. In the end, it goes back to the lawn, where the girl is turning over the calendar for the famous stars on it, meanwhile enjoying the delicious combo pack (For the video, refer to http://video.sina.com.cn/v/b/16513695-1552247590.html).

Table 1

Comparison Between KFC (Kentucky Fried Chicken) and Tsingtao Beer

\begin{tabular}{|l|l|l|}
\hline Commercial & KFC & Tsingtao Beer \\
\hline Denotation & $\begin{array}{l}\text { Tree, grassland, swing; a pretty young Chinese lady; } \\
\text { tomato, lettuce, cereal, pea, corn, apples... a calendar, } \\
\text { KFC hamburger combo pack }\end{array}$ & $\begin{array}{l}\text { A jubilant party, a group of rapturous young people } \\
\text { music; bottles of Tsingtao beer spilling }\end{array}$ \\
\hline Connotation & $\begin{array}{l}\text { Pastoral life, the harmony of Nature and Ma, healthy } \\
\text { food easy life style entertainment in life }\end{array}$ & $\begin{array}{l}\text { Youth and energy release of enthusiasm, display of } \\
\text { individualism exciting life }\end{array}$ \\
\hline
\end{tabular}

The first general impression upon this is fresh, comfy, and natural. Also, the harmony is rather impressive: green and the color of the girl's clothes, the girl, and nature. Definitely, we cannot be the girl after eating the chicken hamburger. However, this commercial seems to appeal to us that we can get the same pastoral pleasure as the girl if we get the combo pack from KFC. In Table 1, we can see the iconic signs (denotation) have some particular connotation for Chinese, i.e., they refer to a kind of pastoral life we urban people yearn for, a kind of 
healthy life we pursue, and a kind of harmony we value. On one hand, the commercial meet the traditional value of Chinese (pursuing the harmony, which is in conformity with the teachings of Daoism and Confucianism); on the other hand, it is advocating a different kind of eating culture from the traditional one, the fast food. Of course, with the development of the society, fast food has been accepted and very popular, but the idea KFC promotes fast food with the traditional idea of harmony with nature is really smart. In addition, from the video, we can get the feeling that people can enjoy fast food in a slow pace, which well catch the psychology of most of the Chinese consumers. Also, the calendar stands for a kind of entertainment, choice of the stars on it depends on one's personality, which is fit for the individualistic and youth value in American society. In fact, the main target consumer of KFC is the young people who are easy to accept new ideas, thus the Western culture can proliferate easily and quickly in an unconscious and intangible way.

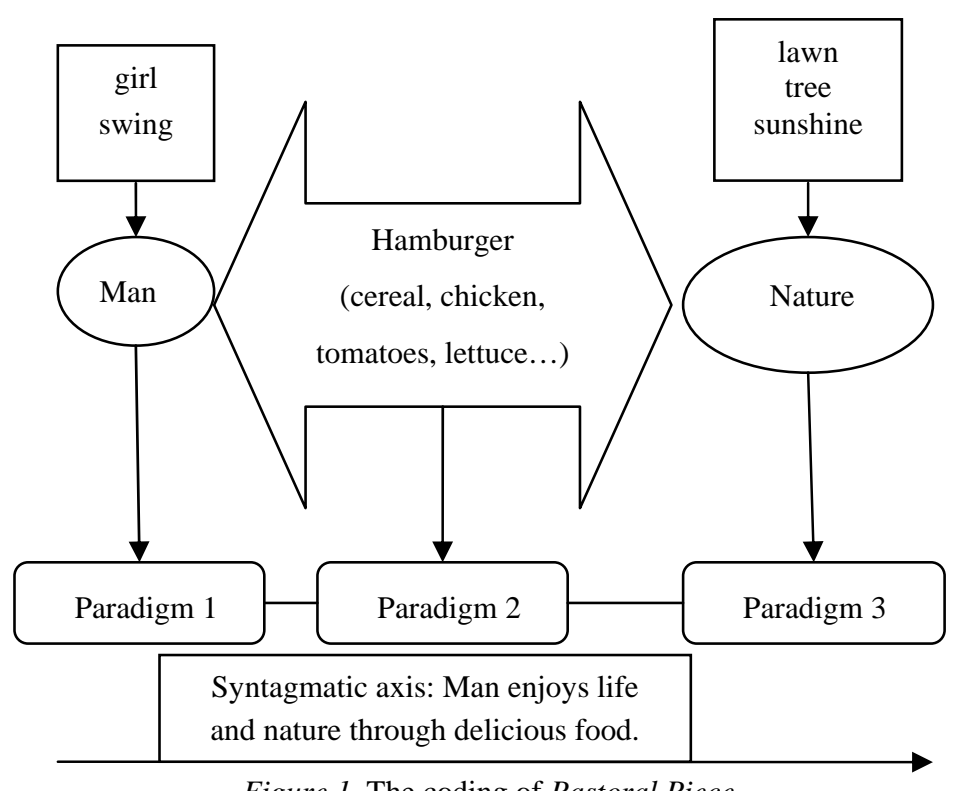

Figure 1. The coding of Pastoral Piece.

From Figure 1, this commercial is obviously sending us the message that life tastes better with the hamburger and man can enjoy nature in a better way. According to Abraham Maslow, the self-actualization need is the highest among the five human needs and the physiological is the most fundamental one (as cited in XU, 2004). In this sense, this commercial not only provides us the food but also the highest-level satisfaction.

Another worth mentioning is the remarks by the girl: "I wish my Mr. Right could be more handsome, but could not be a playboy; I'd like to keep fit but hate to do more extra exercises; I'd like to enjoy more delicious

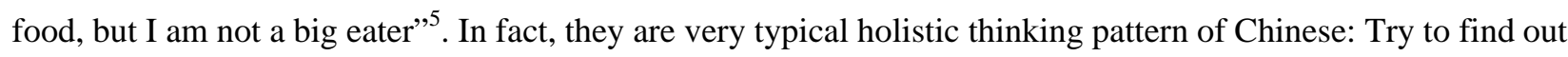
a balancing point between two completely contradictory sides and get more benefit as possible as could be from one thing. Therefore, it also illustrates why KFC hamburger is very popular. However, the commercial itself adopts an analytic way to show this integrated idea: first, the picture of various fruits and cereals; and then, the section of a hamburger. Of course, the thinking pattern is difficult to change, but with such commercials, it is really worth exploring whether it will influence the way of thinking.

${ }^{5}$ Retrieved from http://video.sina.com.cn/v/b/16513695-1552247590.html. 


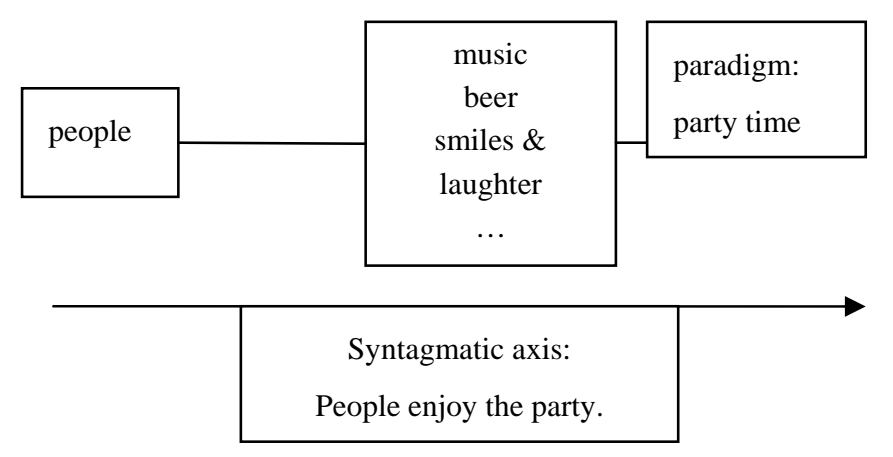

Figure 2. The coding of Tsingtao Beer.

Let us move to the Tsingtao Beer. In this commercial, a group of young people are celebrating with the joyful and enthusiastic background music, cheering and dancing. In spite of no dialogue, from their body posture and facial expression we can get the connotation (as shown in Table 1). This commercial tries to grip the customers to value their individuality, release their enthusiasm and enjoy to their heart, which can to some extent meet the cultural values of Americans. Perhaps this is the very reason it is played on CCTV International. However, this commercial fails to convey the Chinese spirits culture. From Figure 2, we can see the commercial contains less concrete information comparing with the KFC and it only means to stress the happy party time.

In the Shanghai Expo in 2010, one billboard of Tsingtao Beer says: In China, there is a penalty for those who arrives late: Go down three Beers, the purpose of which is to make foreigner understand the spirit of Chinese, i.e., friendly and straightforward. Personally, it is recommended. It would be better if we can advocate our traditional values (cultural heritage) to the others through the commercials for they can get the foreigners to know China in a better and deeper way.

\section{Case Study 2: Nike vs. Seven Brand Garment}

In this part, another two cases will be given. One is from Nike in 2008 and the other is the traditional men's wear Seven Brand.

The Nike commercials tend to be featured by the exciting pictures, rhythmic music, and a lot of information, so is the selected one. With the fast switch of each picture, we can feel the movement, the core spirit of Nike. From one sportsman's opening up of the two hands overhead to the blooming of the flower to the fetus in the womb plus the caption: Everything you need is already inside, we can see the preparatory stage before the games. Then the picture goes quickly to the first step of a baby, the first step in space and the first step of the sportsmen, which is the second stage: release of potential; next is the growing stage with the picture of toddlers. Then followed is the frustration stage with the disappointing face and the injured sportsman in a stretcher. Victories finally come accompanied with the joyful weep and kissing the football and the exciting facial expressions. The last scene is impressive, a man is still running, which shows the sports and sports spirit is ceaseless: "Just do it". The whole commercial is so animated and coherent that you can even breathe with each change of every picture (For video, refer to http://qun.51.com/xiaxinfan/topic.php?pid=3152).

Also, this video has displayed the relation between Man and Animal, the sports are similar to some animals, such as the herd of antelopes waiting to run and the running herd of buffalos. Since this commercial is specially made for the Olympics, so it contains such Chinese factors as the runner LIU Xiang, the Chinese gym athlete and 
Peking opera masks to meet the Chinese consumers. However, the American values are well-represented through the interpretation of the connotations of the signs (see Table 2). First, it is the do-culture that has been fully embodied in the slogan and the originality of the pictures. Second, it displays the frontier spirit of America, i.e., man can conquer nature and challenge the limit. Last, action speaks louder than words.

Table 2

\section{Comparison Between Nike and Seven Brand Garment}

\begin{tabular}{|c|c|c|}
\hline Commercial & Nike & Seven Brand garment \\
\hline Denotation & $\begin{array}{l}\text { Sportsmen, flower, ball, fetus in the womb, toddler, raceway, } \\
\text { gym, football, astronaut, antelopes, buffalos, totem, Peking } \\
\text { opera mask, stretcher... background music } \\
\text { Caption: Everything you need is already inside; Just do it; The } \\
\text { sign of Nike }\end{array}$ & $\begin{array}{l}\text { Lilianjie (famous Kungfu star), a woman, a } \\
\text { wardrobe of clothes), cheering group of people, } \\
\text { wedding, white shoes red wedding dress, white } \\
\text { suits, caption: Seven Brand... }\end{array}$ \\
\hline Conn & $\begin{array}{l}\text { preparation-release of potential-frustration and } \\
\text { failure-victory-go ahead, speed and power, reach one's full } \\
\text { potential, to act }\end{array}$ & in \\
\hline
\end{tabular}

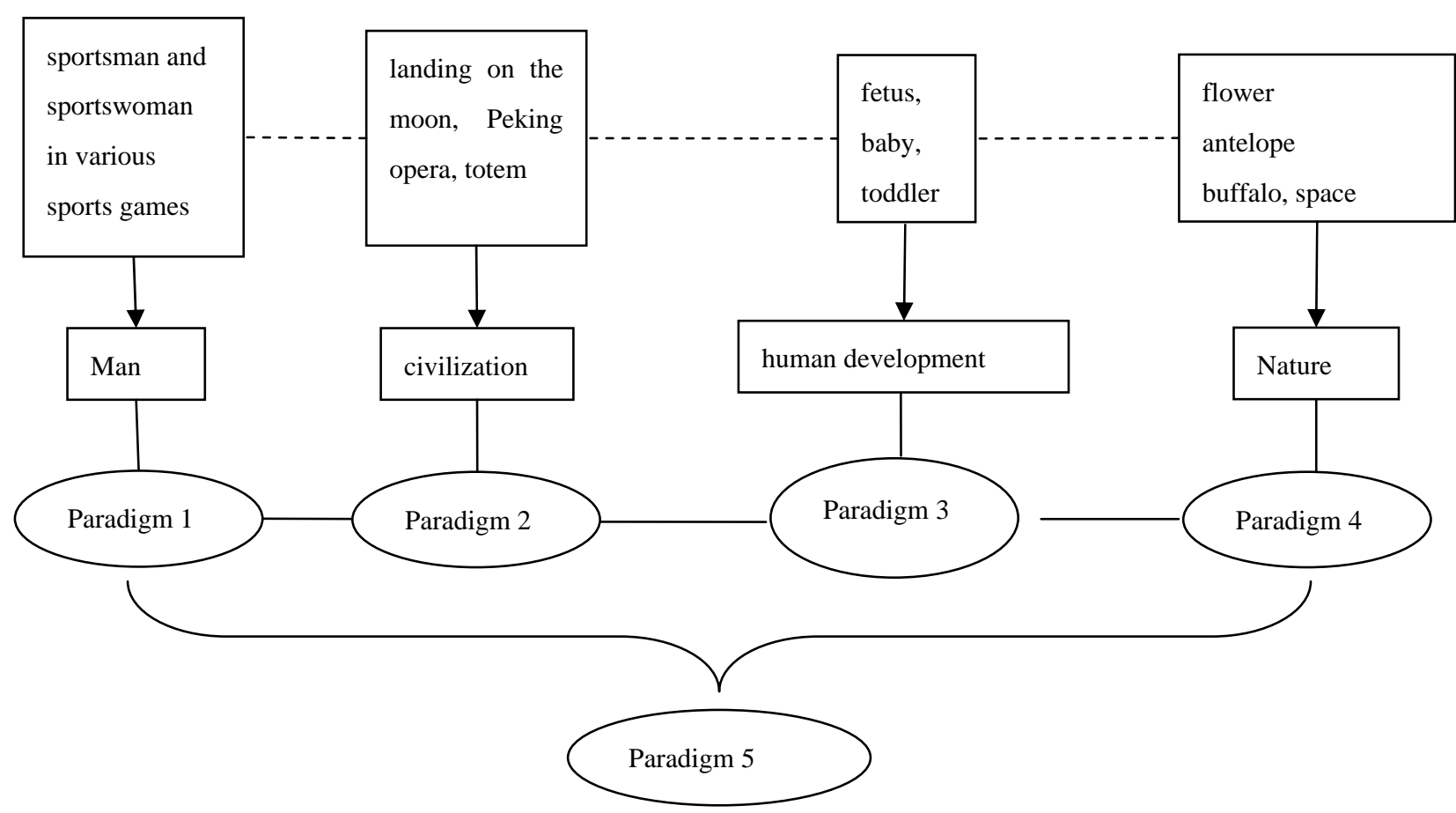

Figure 3. The coding of Nike.

As is shown in Figure 3, this commercial has shown five paradigms: man, human development, civilization, nature, and movement (paradigm 5). As to the syntagmatism, it refers to the five stages of sportsman mentioned above which are shown through the alternate appearance of the signs from the five paradigms (this is shown in dotted line in Figure 3). Comparing with the KFC commercial above, it stresses the conquest or challenge of Nature instead of the harmony with nature. Also, from the Figure 3, it is clearly seen that the good commercial usually centers a theme no matter how many elements are adopted, the arrangement of which is well-organized.

Comparing with the enthusiastic and energetic Nike, the commercial of Seven Brand Men's garment seems more implicit. As Jet Li is well-known to every household in America as Kungfu star, especially after joining the Hollywood, this is the reason he is chosen as the spokesperson. In the commercial, he does not make any actions, 
however, he fully displays the implicitness and elegance of the traditional garment with the loving gesture and eye-contact. As to the connotation (see Table 2), perhaps Chinese and American will have different understanding. For Chinese, the garment stands for integrity, and Americans probably hold wearing the Seven Brand garment will be heroic. In addition, "seven” is an auspicious number in English, such as seventh heaven of delight, seven wise masters, but it has been given religious color, it is not known whether the Americans like the brand name or not. In some sense, the implicitness seems difficult to be understood by the people in high-context culture, for the latter are used to the explicit codes. As to the color of the garment, the white is the key tone, which seems to meet the white wedding in the Western countries. However, it is the bride that wears the white dress instead of the bride. Still, in the commercial, the bride wears the red one and is not given a front face. Hence, this commercial fails to convey the features of the traditional Chinese wedding with this opportunity though the bridegroom wears the red one which represents happiness for Chinese (for video, refer to http://video.sina.com.cn/v/b/479557-1260974451.html).

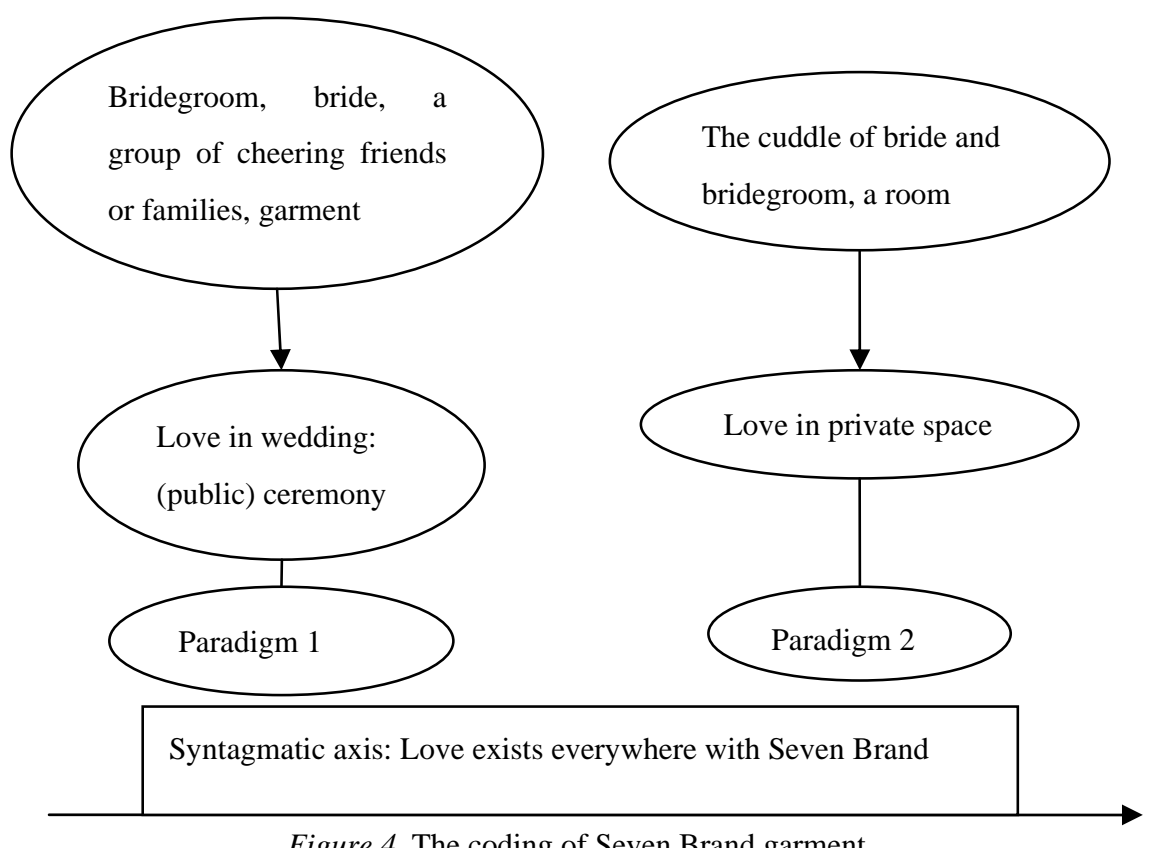

Figure 4. The coding of Seven Brand garment.

As is shown in Figure 4, the topic of this advertising is the affectionate love, which is the eternal topic for people all over the world. The typical way to show the love is implicit.

\section{Characteristics of the Cultural Value Diffusion Between China and America}

From the case study above, we can draw the conclusion as follows.

First, the American culture falls into high-context, and Chinese low-context. It seems high-context code is easier to be understood by people in the low-context, however, it is not so if vice versa. In this sense, the cultural values in high context culture are relatively easy to be accepted and borrowed in the low-context culture.

Second, from Table 1 and Table 2, American commercials obviously contain more information than the Chinese one. The core ideas are often carried in the elements, the American commercials can make the best use of the elements to deal with the localization and its own values. In most cases, its core values are hidden in the explicit elements which seem to always meet the local culture and thus win more chances to spread its own 
cultural values. However, Chinese commercials seem to be weak in doing this. The implicitness is often shown in an implicit way, thus the Chinese characteristic cannot be well understood and accepted.

In fact, this can also be well illustrated with four figures in the paper. The syntagmatism and paradigm in American commercials would be multi-levels and concern such basic questions as the relation between man and nature as well as the high-level satisfaction, thus providing an opportunity to display its core values.

Third, basically speaking, the dominant culture in the world is Western-oriented, typically represented by America. With the abundant introduction of films and greatly exposed to the mass media, some Chinese consumer, especially young generation, are more sensitive to the connotation of the commercials quickly, so the spread of its cultural value is feasible, effective, and convenient.

Fourth, the interaction of the Chinese and American values in the commercials have touched upon the core values, yet it is the one-directional, i.e., the spread of American values such as youth culture, do culture and individualism to China.

The question that the core values centering the Confucianism will change or not is really worth exploring, for the era has changed a lot and young people is different from the old generation. Therefore, we are facing a problem how to safeguard our valuable traditional values facing the great impacts of the Western cultural values.

\section{Conclusions}

On the whole, the diffusion or the interaction of the cultural values can both be negative and positive. On one hand, it will give some guidance to the businessman on how to promote products and value the quality and reputation. On the other hand, as mentioned above we are facing the loss of some traditional virtues, such as being frugal and family-oriented. In addition, some young people are blind in choosing the values and are inclined to lose themselves. Therefore, the spread or borrowing of the cultural values is influential in the cross-cultural commercials, which should be valued and better used so as to safeguard and advocate our good traditional values that really represent Chinese.

\section{References}

Ahmed, N. (2000). Cross-cultural content analysis of advertising from the United States and India. Retrieved from http://www.bookpump.com/dps/pdf-b/1120842b.pdf

Barthes, R. (1967). Elements of semiology. (A. Lavers \& C. Smith, Trans.). London: Jonathan Cape.

CHEN, G. M., \& Starosta, W. J. (2007). Foudations of intercultural communication. Shanghai: Shanghai Foreign Language Educaiton Press.

Cutler, B. D., \& Javalgi, R. G. (1992). A cross-cultural analysis of the visual components of print advertising: The U.S. and the European community. Journal of Advertising Research, 32(1), 71-80.

Rumbaut, R. G. (2005). The melting and the pot: Assimilation and variety in American life. Incorporating diversity: Rethinking assimilation in a multicultural era (pp. 154-173). Boulder, C.O.: Paradigm Publishers.

Samovar, L. A., \& Porter, R. E. (2000). Communication between cultures (p. 45). Beijing: Foreign Language Teaching and Research Press.

Saussure. F. De. (2013). Course in general linguisitcs. (R. Harris Trans.). Beijing: Foreign Teaching and Research and Research Press \& Gerald Duckworth \& Co.Ltd..

Weinberger, M. G. \& Spotts, H. E. (1989). Humor in U.S. versus U.K. TV commercials: A comparison. Journal of Advertising, $18(2)$.

Wiki. (n.d.). What is cultural diffusion?. Retrieved from_http://wiki.answers.com/Q/What_is_cultural_diffusion

XU, L. S. (2004). Intercultural communication in English (p. 41). Shanghai: Shanghai Foreign Language Education Press. 